Clinical Image

\title{
Dermoscopy of awartarising in a melanocytic nevus
}

\section{Clinical image}

A 20 year-old presented to our consultation because of a 1-month apparition of new lesion within the nevus avec occasional bledding . Clinical examination found $2 \mathrm{~mm}$ white and keratosic papule located exclusively on the surface of the nevus (Figure1). The nevus $(6 \times 4 \mathrm{~mm})$ was centered by a terminal hair and had a papillomatous pattern. Dermoscopy of the lesion showed filiform exophytic projection pattern with hair pin vessels (Figure $2 \& 3$ ). The clinical evaluation with the help of dermoscopy was compatible with the diagnosis of was within naevus. We performed a excision biopsy for histopathologic examination, which showed proliferation of melanocytes in the dermis, cutaneous hypeplasia, compact orthokeratosis and tortuous capillaries with the dermal papillae. No recurrence has appearedduring1 year of follow up since then.

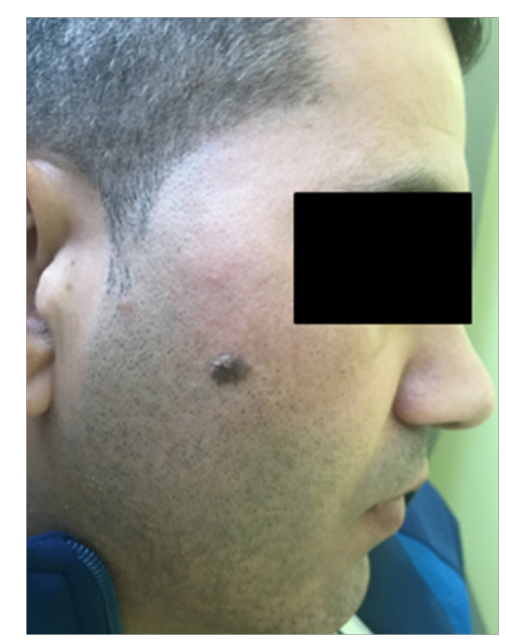

Figure I Melanocytic nevus of the cheek in a 25 -year-old male patient.
Volume 3 Issue 6 - 2019

Selma El kadiri, Chaoui R, Douhi Z, Elloudi S, BayBay H, Mernissi FZ

Department of Dermatology, CHU Hassan II, Morocco

Correspondence: Selma El kadiri, Department of Dermatology, CHU Hassan II, Fez, Morocco,

Email elkadiri-@hotmail.com

Received: November II, 2019 | Published: December 31, 2019
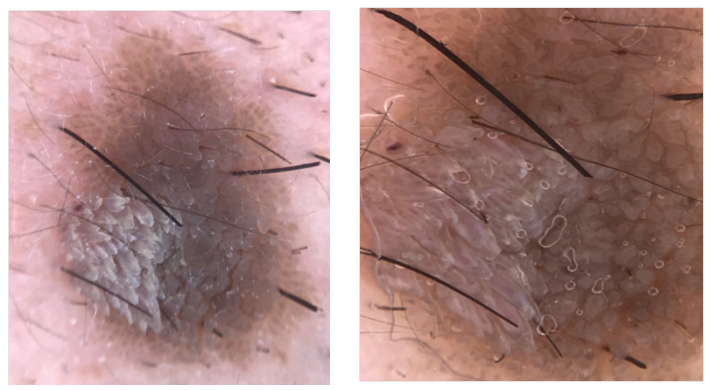

Figure 2-3 Filiform exophytic projection pattern (without immersion figure 2 ) with hair pin vessels ( with immersion figure 3 ).

\section{Acknowledgment \& funding}

None.

\section{Conflicts of interest}

The authors declare that there are no conflicts of interest. 